\title{
Bacteriological Profile of Uropathogens and their Antimicrobial Susceptibility Pattern in Isolates from a Tertiary Care Hospital
}

\author{
Sundararajan Thangavel $^{1}$, Gomathi Maniyan ${ }^{1}$, S. Vijaya ${ }^{2}$ and C. Venkateswaran ${ }^{2}$ \\ ${ }^{1}$ Department of Microbiology, Government Mohan Kumaramangalam Medical College, \\ Salem, Tamil Nadu, India \\ ${ }^{2}$ Lab. Technician, Salem, Tamil Nadu, India \\ *Corresponding author:
}

\section{A B S T R A C T}

\begin{tabular}{|l|}
\hline Ke y w o r d s \\
Urinary tract \\
infection, \\
Antimicrobial \\
susceptibility, \\
Extended-spectrum \\
B-lactamases, \\
Amp C, Metallo Beta \\
Lactamases (MBL). \\
\hline Article Info \\
\hline Accepted: \\
25 April 2017 \\
Available Online: \\
10 May 2017 \\
\hline
\end{tabular}

Urinary Tract Infection (UTI) is one of the most common infections observed in clinical practice among the community and hospitalized patients. Since the pattern of susceptibility is constantly changing, monitoring the changing trends has become more important. It provides information of the pathogenic organisms isolated from patients as well as assists in choosing the appropriate antimicrobial therapy. This retrospective study aims to analyze various uropathogens and their antimicrobial susceptibility pattern which would assist in selecting the most appropriate antibiotic therapy and for treatment of UTI in a tertiary care hospital. 700 urine isolates were studied retrospectively from November 2016 to January2017 which were cultured on to Blood agar and MacConkey agar plate. The plates that showed colonies $>10^{5}$ were considered significant and were identified by standard biochemical tests \& sensitivity of the organisms was performed by Kirby - Bauer method on Mueller Hinton agar. Out of the 700 samples processed,48.6\% (340) gave positive urine culture, of which $73(61.86 \%)$ were Escherichia coli 69\% (107), Klebsiella spp.,11.6\%(18), Proteus spp., 9.7\%(15), pseudomonas spp.,8.4\% (13), Acinetobacter spp.,1.3\%(2) and Coagulase Negative Staphylococcus(CONS) 67\% (130), Candida spp.,24.7\%(48), Enterococci spp., 8.3\%(16) respectively. Susceptibility patterns of each isolates have been determined. Resistance pattern observed was ESBL was about 87\%, MBL 8\% and AmpC7\% among the Gram negative organisms. This study discourages the indiscriminate use of antibiotics which in turn would prevent further development of bacterial drug resistance. For this, a proper knowledge of susceptibility pattern of uropathogens is necessary before prescribing empirical antibiotic therapy.

\section{Introduction}

Urinary Tract Infection (UTI) is one of the most common infections observed in clinical practice among the community\& hospitalized patients (Khan et al., 2001). Despite the widespread availability of antibiotics, UTI remains the most common bacterial infection in human population. Since the antibiotic susceptibility pattern is constantly changing, monitoring the antimicrobial susceptibility has become mandatory (Charania et al., 1980; Gupta et al., 2002). It provides information on the pathogenic organisms isolated from patients as well as assists in choosing the most appropriate antimicrobial therapy (Deshpande et al., 2011). The uses of antibiotics have an influence in the spread of 
antimicrobial resistance among bacteria. Antibiotic resistant microorganisms have been a source of ever-increasing therapeutic problem. Continued mismanaged selective pressure has contributed towards the emergence of multiple drug resistant (MDR) bacteria (Cohen et al., 1992). Treatment of UTI cases is often started empirically and therapy is based on information determined from the antimicrobial resistance pattern of the urinary pathogens. In spite of the availability and use of the antimicrobial drugs, UTIs caused by bacteria have been showing increasing trends in recent years (Razak et al., 2012). The emergence of antibiotic resistance in the management of UTIs is a serious public health issue, particularly in the developing world where apart from high level of poverty, ignorance and poor hygienic practices, there is also high prevalence of fake and spurious drugs of questionable quality in circulation. The current knowledge of susceptibility pattern is mandatory for the proper management of UTI.

This retrospective study aims to analyze various uropathogens and their antimicrobial susceptibility pattern in a tertiary care hospital, which assist in selecting the most appropriate antibiotic therapy in treatment of Urinary Tract Infection.

\section{Materials and Methods}

A retrospective analysis of 700 consecutive urine samples received at the microbiology laboratory in a tertiary care hospital over a period of 3 months from November 2016 to January 2017. Samples were mid - stream urine specimens obtained by clean catch method received from various outpatient departments and inpatient wards were transported to the diagnostic laboratory in sterile leak proof container were processed immediately.
All the specimens were inoculated onto Blood agar and MacConkey agar plate and incubated overnight at $37^{\circ} \mathrm{C}$. Samples that showed a colony count of $>10^{5}$ were considered significant. Bacterial isolates were identified based on the colony morphology, Grams staining and biochemical reactions. Antimicrobial susceptibility testing was done using Muller Hinton agar by modified KirbyBauer disc diffusion method and their resistance pattern was analyzed according to CLSI guidelines 2016. The data was recorded and analyzed.

Antimicrobial Agents used: Ampicillin $(10 \mu \mathrm{g})$, Amikacin $(30 \mu \mathrm{g}), \quad$ Gentamycin $(10 \mu \mathrm{g}), \quad$ Ciprofloxacin $(5 \mu \mathrm{g})$, Cefotaxime $(30 \mu \mathrm{g})$, Ceftriaxone $(30 \mu \mathrm{g})$, cefepime $(30 \mu \mathrm{g})$, Cotrimoxazole $(1.25 / 23.75 \mu \mathrm{g})$, Norfloxacin $(10 \mu \mathrm{g})$, Ciprofloxacin $(5 \mu \mathrm{g})$, Ofloxacin $(5 \mu \mathrm{g})$, Nitrofurantoin $(300 \mu \mathrm{g})$, Imipenem $(10 \mu \mathrm{g})$, Meropenem $(10 \mu \mathrm{g})$, Piperacillin-tazobactum, $(100 / 10 \mu g)$, Vancomycin $(30 \mu \mathrm{g})$, Linezolid

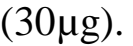

\section{Results and Discussion}

A total of 700 urine culture reports were analyzed in the present study between November 2016 and January 2017. Among the total of 700 samples received, $48.6 \%$ (340) showed positivity for microbial growth and $2.7 \%$ (9) were polymicrobial (Table 1). The predominant growth of single bacteria was seen in $97.3 \%$ (331) samples out of which $52.9 \%$ (180) were females and $47.1 \%$ (160) were males (Table2), $54 \%$ (183) from outpatient and $46 \%$ (157) from inpatient department. Among the organisms isolated Gram positive was 56\%(194) and Gram negative was 44\%(155). The most common organisms isolated were Escherichia coli $69 \%$ (107), Klebsiella spp.,11.6\% (18), Proteus spp., 9.7\%(15), Pseudomonas spp.,8.4\%(13), Acinetobacter spp.,1.3\%(2) and Coagulase Negative Staphylococcus (CONS) 67\%(130), 
Candida spp., 24.7\%(48), Enterococci spp., $8.3 \%$ (16) respectively (Table 3). Enterococci spp., showed $100 \%$ susceptibility to vancomycin and Linezolid, 68.8\% sensitivity to Ampicillin and $56.3 \%$ sensitivity to Nitrofurantoin (Table 4). E. coli showed 96.3\% sensitivity to Amikacin, Imipenem and Meropenem, $94.4 \%$ sensitivity to Piperacillintazobactum. $\quad 89.7 \%$ sensitivity to Nitrofurantoin. Klebsiella showed $94.4 \%$ sensitivity to Imipenem and Meropenem and $72.2 \%$ to pip-taz and Amikacin. Proteus showed $100 \%$ sensitivity to Imipenem, Meropenem and pip-taz., $86.7 \%$ sensitivity to Amikacin and $60 \%$ sensitivity to Ciprofloxacin and Ofloxacin. Pseudomonas spp., showed $76.9 \%$ sensitivity to pip-taz, Imipenem and Meropenem, 69.2\% sensitivity to Cefipime and $61.5 \%$ sensitivity to Ciprofloxacin, Ofloxacin and Amikacin. Acinetobacter spp., showed $100 \%$ sensitivity to Amikacin, all the cephalosporins, pip-taz and carbapenems (Table 5). Regarding the drug resistance pattern, $E$. coli showed $65.4 \%$ (70) of ESBL, AmpC 2.8\% (3) and MBL 3.7\%(4), Klebsiella spp., showed ESBL 44.4\%(8), 22.2\%(4) AmpC and MBL5.6\% (1). In Proteus spp., there were $60 \%$ (9) ESBL producers and in Pseudomonas spp., there were $23.1 \%$ (3) MBL producers (Table 6).

Urine culture is very much important for the treatment of UTI in both males and females. It is also essential to isolate and identify the bacteria which cause urinary tract infection. In addition to that the susceptibility pattern of these bacteria is very important to avoid the development of drug resistance. A total of 700 urine culture reports were analyzed in the present study between November 2016 and January 2017. In the present study, isolation and identification of uropathogens were performed and $48.6 \%$ (340) showed significant growth of bacteria. So, remaining majority $51.4 \%$ (360) of the cases showed either insignificant bacteriuria or no growth with urine from the suspected cases of UTI. The reason of low growth rate may be due to irrational use of antibiotic which is available in the local market in this country and these are given without prior culture and antibiotic sensitivity pattern. In addition to that, incomplete dose is another factor. Prior antibiotic therapy before sending urine samples for culture and sensitivity and other clinical conditions like non-gonococcal urethritis could be the factors responsible for insignificant bacteriuria or no growth. Among the total of 700 samples received, 2.7\%(9) were polymicrobial, the predominant growth of single bacteria was seen in $97.3 \%$ (331) samples out of which $52.9 \%$ (180) were females and $47.1 \%(160)$ were males. The male to female ratio was $1: 1.125$ and $54 \%$ (183) from outpatient and $46 \%$ (157) from inpatient department. The age and sex distribution of the patients diagnosed with UTI among the hospitalized patients and those attending the outpatient department followed the natural epidemiological pattern of UTI. There were a higher number of young adult female patients diagnosed as UTI cases. Yusuf et al., showed the ratio is more than two times more frequent in female than male (ratio male: female $=1: 2.2$ ).

It is well established that female are more commonly infected with UTI than male due to anatomical position of urethra, influence of hormone and pregnancy. The international studies have shown that UTIs in women are very common; therefore, one in five adult women experience UTI in her life and it is extremely common, clinically apparent, worldwide patient problem (Abdullah et al., 2015). Among the organisms isolated Gram positive was 56\% (194) and Gram negative was $44 \%$ (155). The most common organisms isolated from this study were Escherichia coli 69\%(107), Klebsiella spp.,11.6\%(18), Proteus spp., 9.7\%(15), Pseudomonas spp., 8.4\%(13), Acinetobacter spp., 1.3\%(2), Coagulase Negative Staphylococcus 
67\%(130), Candida spp., 24.7\%(48), which correlates with the study conducted by Mathivathana, Usha et al., (2013) which showed isolation of $(61.86 \%)$ were Escherichia coli, (18.64\%) were Klebsiella spp., $\quad(12.71 \%)$ were Pseudomonas spp., Proteus spp. (0.08\%) and Acinetobacter spp. $(0.08 \%)$. Polymicrobial infection mounted to $12(10.16 \%) .8$ isolates of Candida were obtained. Gram-positive organisms have received more attention recently as a cause for bacteriuria and UTI. Coagulase negative Staphylococcus, S. aureus, streptococci, and Enterococci have been reported in small numbers by various authors, but they are recognized as important causes of UTI. Enterococci spp., $8.3 \%$ (16) were isolated. Enterococci spp., showed 100\% susceptibility to vancomycin and Linezolid, $68.8 \%$ sensitivity to Ampicillin and 56.3\% sensitivity to Nitrofurantoin. We found similar occurrence rate as $13.5 \%$, and $5.8 \%$ for Enterococci, and Coagulase negative Staphylococcus, respectively and 23 cases of candiduria. In our study, E.coli showed $96.3 \%$ sensitivity to Amikacin, Imipenem and Meropenem, 94.4\% sensitivity to Pip-taz. $89.7 \%$ sensitivity to Nitrofurantoin. Klebsiella showed $94.4 \%$ sensitivity to Imipenem and Meropenem and $72.2 \%$ to pip-taz and Amikacin. Proteus showed 100\% sensitivity to Imipenem, Meropenem and pip-taz.86.7\% sensitivity to Amikacin and $60 \%$ sensitivity to Ciprofloxacin and Ofloxacin. Pseudomonas spp., showed $76.9 \%$ sensitivity to pip-taz, Imipenem and Meropenem69.2\% sensitivity to Cefipime and $61.5 \%$ sensitivity to Ciprofloxacin, Ofloxacin and Amikacin. Acinetobacter spp., showed $100 \%$ sensitivity to Amikacin, all the cephalosporins, pip-taz and carbapenems. Similar study by Mathivathana et al., showed overall Sensitivity to Imipenem was $100 \%$, Nitrofurantoin was $90.57 \%$, Amikacin was $83.02 \%$, fourth generation cephalosporin was
43.4\%, Fluoroquinolones was $32.1 \%$ and Third Generation Cephalosporin was $30.8 \%$.

Regarding the drug resistance pattern, in the present study, E.coli showed 65.4\%(70) of ESBL, AmpC 2.8\% (3) and MBL 3.7\%(4), Klebsiella spp., showed ESBL 44.4\%(8), $22.2 \%$ (4) AmpC and MBL5.6\% (1). In Proteus spp., there were 60\% (9) ESBL producers. Another study showed the percentage of ESBL producers was $69.2 \%$. Maximum ESBL producers were found among $E$. coli isolates i.e. $80.9 \%$ followed by Klebsiella spp., (75\%). A study done by Mathur et al., (2011) and Umadevi et al., (2002) showed $68 \%$ and $75 \%$ prevalence of ESBL producers respectively. Additionally, Extended-spectrum $\beta$-lactamase (ESBL)producing $E$. coli tended to be isolated more often in these studies. In another recent study $29.5 \%$ of E. coli were suspected to produce Extended-spectrum beta-lactamase (ESBL) and amikacin and nitrofurantoin were the drugs to which $>90 \%$ of $E$. coli were susceptible. E. coli was found to be sensitive to imipenem (97.9\%) followed by nitrofurantoin $(91.5 \%)$, amikacin $(76.6 \%)$ and piperacillin-tazobactam (68\%). Babypadmini et al., showed the susceptibility of ESBL producers to imipenem, nitrofurantoin and amikacin to be $100 \%, 89 \%$ and $86 \%$ respectively. In the present study, Amp C production was $25 \%$ of which $22.2 \%$ (4) from Klebsiella spp., and 2.8\% (2) from E.coli. Study conducted by Mitesh patel et al., (2010) showed (45.61\%) were positive for AmpC $\beta$ lactamase enzyme production. In the present study, MBL production was observed in 32.4\%. In Pseudomonas spp., there were 23.1\%(3) MBL producers. Sowmya et al., (2015) showed $15.3 \%$ Imipenem resistance among Pseudomonas strains, however a higher resistance rate have been reported by Varaiya et al., (2015) (25\%). 
Table.1 Growth of Urine culture among the study population ( $\mathrm{n}=700)$

\begin{tabular}{|l|c|c|}
\hline Growth & Number & Percentage(\%) \\
\hline Positive & 340 & 48.6 \\
\hline Polymicrobial & 9 & 2.7 \\
\hline Monomicrobial & 331 & 97.3 \\
\hline No growth & 360 & 51.4 \\
\hline
\end{tabular}

Growth of Urine culture among the study population $(\mathbf{n}=700)$

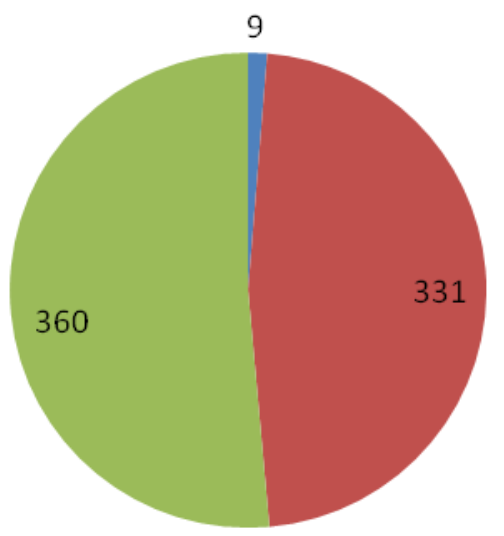

Polymicrobial

- Monomicrobial

Nogrowth

Table.2 Gender distribution of culture positive cases(n=340)

\begin{tabular}{|c|c|c|}
\hline Gender & Number & Percentage $(\%)$ \\
\hline Female & 180 & 52.9 \\
\hline Male & 160 & 47.1 \\
\hline
\end{tabular}

Table 2: Gender distribution of culture positive cases $(n=340)$

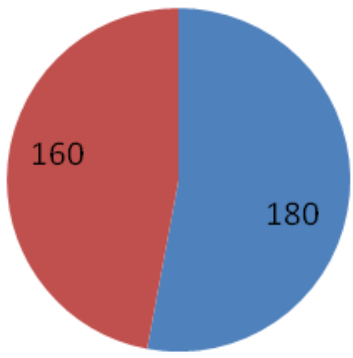


Table.3 Bacteriological profile of Culture positive organisms ( $\mathrm{n}=340$ )

\begin{tabular}{|l|c|c|}
\hline \multicolumn{1}{|c|}{ Bacteria } & Number & Percentage(\%) \\
\hline Escherichia coli & 107 & 69 \\
\hline Klebsiella spp., & 18 & 11.6 \\
\hline Proteus spp., & 15 & 9.7 \\
\hline Pseudomonas spp., & 13 & 8.4 \\
\hline Acinetobacter spp., & 2 & 1.3 \\
\hline CONS & 130 & 67 \\
\hline Candida spp., & 48 & 24.7 \\
\hline Enterococci spp., & 16 & 8.3 \\
\hline
\end{tabular}

Table.4 Antimicrobial susceptibility pattern of Enterococci spp., (n=16)

\begin{tabular}{|c|c|c|c|c|}
\hline Antibiotics & $\mathrm{S}$ & $\%$ & $\mathrm{R}$ & $\%$ \\
\hline Ampicillin $(10 \mu \mathrm{g})$ & 11 & 68.8 & 5 & 31 \\
\hline Amikacin $(10 \mu \mathrm{g})$ & 6 & 37.5 & 10 & 63 \\
\hline High level Gentamycin $(120 \mu \mathrm{g}$ & 6 & 37.5 & 10 & 63 \\
\hline Norfloxacin $10 \mu \mathrm{g}$ & 1 & 6.25 & 15 & 94 \\
\hline Ciprofloxacin $5 \mu \mathrm{g}$ & 1 & 6.25 & 15 & 94 \\
\hline Nitrofurantoin $300 \mu \mathrm{g}$ & 9 & 56.3 & 7 & 44 \\
\hline 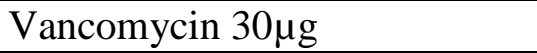 & 16 & 100 & 0 & 0 \\
\hline 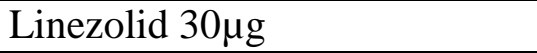 & 16 & 100 & 0 & 0 \\
\hline
\end{tabular}

Table.6 Distribution of antimicrobial resistance pattern among the isolates

\begin{tabular}{|l|c|c|c|}
\hline \multicolumn{1}{|c|}{ Organism } & $\begin{array}{c}\text { ESBL } \\
(\mathrm{No} / \%)\end{array}$ & $\begin{array}{c}\text { AMP C } \\
(\mathrm{No} / \%)\end{array}$ & $\begin{array}{c}\text { MBL } \\
(\mathrm{No} / \%)\end{array}$ \\
\hline E.coli $(\mathrm{n}=107)$ & $70(65.4)$ & $3(2.8)$ & $4(3.7)$ \\
\hline Klebsiella spp.,(n=18) & $8(44.4)$ & $4(22.2)$ & $1(5.6)$ \\
\hline Proteus spp.,(n=15) & $9(60)$ & - & - \\
\hline Pseudomonas spp.,(n=13) & - & - & $3(23.1)$ \\
\hline
\end{tabular}


Table.5 Antimicrobial susceptibility pattern of Gram negative organism $(n=155)$

\begin{tabular}{|c|c|c|c|c|c|}
\hline Antibiotics & $\begin{array}{c}\text { E.coli }(n=107) \\
(\mathrm{No} / \%)\end{array}$ & $\begin{array}{c}\text { Klebsiella } \\
\text { spp., }(\mathrm{n}=18) \\
(\mathrm{No} / \%)\end{array}$ & $\begin{array}{c}\text { Proteus } \\
\text { spp., }(\mathrm{n}=15) \\
(\mathrm{No} / \%)\end{array}$ & $\begin{array}{c}\text { Pseudomonas } \\
\text { spp., }(\mathrm{n}=13) \\
(\mathrm{No} / \%)\end{array}$ & $\begin{array}{c}\text { Acinetobacter } \\
\text { spp., }(\mathrm{n}=2) \\
(\mathrm{No} / \%)\end{array}$ \\
\hline Ampicillin $(10 \mu \mathrm{g})$ & $9(8.4)$ & $0(0)$ & $1(6.7)$ & - & - \\
\hline Amikacin $(30 \mu \mathrm{g})$ & 103(96.3) & $13(72.2)$ & 13(86.7) & $8(61.5)$ & $2(100)$ \\
\hline Gentamycin $(10 \mu \mathrm{g})$ & $55(51.4)$ & $8(44.4)$ & $10(66.7)$ & $5(38.5)$ & $1(50)$ \\
\hline Norfloxacin $(10 \mu \mathrm{g})$ & $30(28)$ & $7(38.9)$ & $8(53.3)$ & $5(38.5)$ & $1(50)$ \\
\hline Ciprofloxacin $(5 \mu \mathrm{g})$ & $30(28)$ & $7(38.9)$ & $9(60)$ & $8(61.5)$ & $1(50)$ \\
\hline Ofloxacin $(5 \mu \mathrm{g})$ & $31(29)$ & $7(38.9)$ & $9(60)$ & $8(61.5)$ & $1(50)$ \\
\hline Ceftriaxone $(30 \mu \mathrm{g})$ & $29(27.1)$ & $5(27.8)$ & $6(40)$ & 0 & $2(100)$ \\
\hline Cefotaxime $(30 \mu \mathrm{g})$ & $27(25.2)$ & $5(27.8)$ & $6(40)$ & - & $2(100)$ \\
\hline Cefipime $(30 \mu \mathrm{g})$ & $37(34.6)$ & $6(33.3)$ & $7(46.7)$ & $9(69.2)$ & $2(100)$ \\
\hline $\begin{array}{l}\text { Cotrimoxazole }(1.25 / 23 . \\
75 \mu \mathrm{g})\end{array}$ & $35(32.7)$ & $4(22.2)$ & $3(20)$ & - & $1(50)$ \\
\hline Nitrofurantoin $(300 \mu \mathrm{g})$ & $96(89.7)$ & $2(11.1)$ & $3(20)$ & - & - \\
\hline $\begin{array}{l}\text { Piperacillin - } \\
\text { tazobactum }(100 / 10 \mu \mathrm{g})\end{array}$ & 101(94.4) & 13(72.2) & $15(100)$ & $10(76.9)$ & $2(100)$ \\
\hline Imipenem $(10 \mu \mathrm{g})$ & $103(96.3)$ & 17(94.4) & $15(100)$ & $10(76.9)$ & $2(100)$ \\
\hline Meropenem $(10 \mu \mathrm{g})$ & $103(96.3)$ & 17(94.4) & $15(100)$ & $10(76.9)$ & $2(100)$ \\
\hline
\end{tabular}

In conclusion, the results of the present study showed that higher rate of resistance is prevalent in a tertiary care hospital, which is the result of the irrational use of antibiotics and implementation of appropriate infection control measures to control the spread of these strains in the hospital.

Moreover, our study concludes that $E$. coli and other isolates were more sensitive to imipenem, nitrofuranotin and piperacillin-tazobactam compared to the other antibiotics tested and therefore these may be the drugs of choice for treatment of infections that are caused by ESBLs. With the increasing use of carbapenems for treating infections with ESBL producing organisms, the problem of MBL production is also increasing. This study discourages the indiscriminate use of antibiotics which helps to curb further development of bacterial drug resistance. For this, a proper knowledge of susceptibility pattern of uropathogens in the given locality is necessary before prescribing empirical antibiotic therapy.

\section{References}

Bours, P.H., Polak, R., Hoepelman, A.I., et al. 2010. Increasing resistance in community-acquired urinary tract infections in Latin America, five years after the implementation of national therapeutic guidelines. Int. J. Infect. Dis., 14(9): 770-4.

Charania, S., Siddiqui, P., Hayat, L. 1980. A study of urinary infections in school going female children. J. Pak. Med. Assoc., 30: 165-167.

CLSI. 2016. Performance standards for antimicrobial susceptibility testing, Clinical and Laboratory Standards Institute Doc. M100. 
Cohen, M.L. and R.V. Auxe. Drugresistant salmonella in the United States:an epidemiological perspective, Sci., 234: 964-970.

Deshpande, K.D., A.P. Pichare, et al. 2011. Antibiogram of Gram negative uropathogens in hospitalized patients. Int. J. Recent Trends in Sci. Technol., Vol 1,Issue 2, 56-60.

Gupta, V., Yadav, A., Joshi, R.M. 2002. Antibiotic resistance pattern in uropathogens. Indian J. Med. Microbiol., 20: 96-8.

Khan, S.W., A. Ahmed. 2001. Uropathogens and their Susceptibility Pattern: a Retrospective Analysis, JPMA, 51: 98.

Manikandan, S., S. Ganesapandian, Manoj Singh and A.K. Kumaraguru. Antimicrobial Susceptibility Pattern ofUrinary Tract Infection Causing Human Pathogenic Bacteria. Asian J. Med. Sci., 3(2): 56-60.

Mathivathana, G., B. Usha, G. Sasikala, K.R. Rajesh, R. Indra Priyadharsini, K.S. Seetha Vinayaka Missions Kirupananda Variyar Medical College, Salem. Gram Negative Uropathogens and their Susceptibility Pattern: A Retrospective Analysis, Int. J. Scientific and Res, Publications, Volume 3, Issue 5, May 20131 ISSN 2250-3153; 1-3.

Mathur, P., Kapil, A., Das, B., Dhawan, B. 2002. Prevalence of extended spectrum beta lactamase producing gram negative bacteria in a tertiary care hospital. Ind. J. Med. Res., 115(4): 153-7.

Md. Abdullah Yusu, Afroza Begum and Chowdhury Rafiqul Ahsan. 2015. Antibiotic sensitivity pattern of gram negative uropathogenic bacilli at a private hospital in Dhaka city US National Library of Medicine enlisted, J. Al Ameen J. Med. Sci., Volume 8, No.3, Al Ameen J. Med. Sci., 8(3): 189-19.

Mitesh, H., Patel, Grishma, R., Trivedi, Sachin, M., Patel, Mahendra, M., Vegad. 2010. Department of Microbiology, B J Medical College, Ahmedabad Antibiotic susceptibility pattern in urinary isolates of gram negative bacilli with special reference to AmpC $\beta$-lactamasein a tertiary care hospital, Urol. Annals, Vol 2, Issue $1 ; 9-1$.

Razak, S.K., Gurushantappa. 2012. Bacteriologyof Urinary Tract Infections and Antibiotic Susceptibility Pattern in a Tertiary care Hospital in South India. Int. J. Med. Sci. Public Health, 1(2): 109-112.

Shikha jain, Geeta walia, Rubina malhotra et al. Prevalence and antimicrobial susceptibility pattern of esbl producing gram negative bacilli in 200 cases of urinary tract infections, Int. J. Pharm. Pharm. Sci., vol 6, issue 10, 210-211.

Sowmya, G., Shivappa, Ranjitha Shankaregowda, Raghavendra Rao, M., Rajeshwari, K.G., Madhuri Kulkarni. 2015. JSS Medical College, Mysore, India. Detection of Metallo-beta lactamase production in clinical isolates of Non fermentative Gram negative bacilli, IOSR J. Dental and Med. Sci., (IOSR-JDMS) e-ISSN: 2279-0853, Volume 14, Issue 10 Ver.VII, pp. 43-48.

Umadevi, S., Kandhakumari, J., Joseph, N.M., Kumar, S., Easow, J.M., Stephen, S., et al. 2011. Prevalence and antimicrobial susceptibility pattern of ESBL producing gram negative bacilli. J. Clin. Diag. Res., 5(2): 236-9.

\section{How to cite this article:}

Sundararajan Thangavel, Gomathi Maniyan, S. Vijaya and Venkateswaran, C. 2017. Bacteriological Profile of Uropathogens and their Antimicrobial Susceptibility Pattern in Isolates from a Tertiary Care Hospital. Int.J.Curr.Microbiol.App.Sci. 6(5): 2279-2286. doi: https://doi.org/10.20546/ijcmas.2017.605.254 